\title{
Integration of human factors principles in LARG organizations - a conceptual model
}

\author{
Sara Figueira ${ }^{\mathrm{a}, *}$, V. Cruz Machado ${ }^{\mathrm{a}, \mathrm{b}}$ and Isabel L. Nunes ${ }^{\mathrm{a}, \mathrm{c}}$ \\ ${ }^{a}$ Departamento Engenharia Mecânica e Industrial, Faculdade de Ciências e Tecnologia / Universidade Nova de \\ Lisboa, Campus de Caparica, 2829-516 Caparica, Portugal \\ ${ }^{\mathrm{b}}$ Unidade de Investigação em Engenharia Mecânica e Industrial, Faculdade de Ciências e Tecnologia I \\ Universidade Nova de Lisboa, Campus de Caparica, 2829-516 Caparica, Portugal \\ ${ }^{\mathrm{C}}$ Centro de Tecnologia e Sistemas, Faculdade de Ciências e Tecnologia / Universidade Nova de Lisboa, Campus \\ de Caparica, 2829-516 Caparica, Portugal
}

\begin{abstract}
Nowadays many companies are undergoing organizational transformations in order to meet the changing market demands. Thus, in order to become more competitive, supply chains (SC) are adopting new management paradigms to improve SC performance: lean, agile, resilient and green (LARG paradigms). The implementation of new production paradigms demands particular care with the issues related with Human Factors to avoid health and safety problems to workers and losses to companies. Thus, the successful introduction of these new production paradigms depends among others on a Human Factors oriented approach. This work presents a conceptual framework that allows integrating ergonomic and safety design principles during the different implementation phases of lean, agile, resilient and green practices.
\end{abstract}

Keywords: Supply chain, LARG paradigms, Conceptual framework, Human factors

* Corresponding author. Tel.: +351 212948 567,+351 212948542 E-mail: ssf15698@fct.unl.pt 


\section{Introduction}

Today's global marketplace requires that organizations do not compete as independent entities, rather as an integral part of a supply chain (SC) [27].

The supply chain, as a network, is expected to provide the right products and services on time, with the required specifications, at the right place to the customer. However, a SC can be quite a complex system; it is usually defined as a set of interdependent organizations that act together to control, manage and improve the flow of materials, products, services and information, from the origin point to the delivery point (the end customer) in order to satisfy the customer needs, at the lowest possible cost to all members (Lampert et al. cited by [4]).

The pressure to cut costs and the unpredictable delivery requirements have resulted in long working hours, a high use of outsourced work and the speeding up of production lines. These indirect supply chain effects may be more of a difficulty for an adequate health and safety at work [19]. Therefore, design, planning and management complex systems will increasingly have to address the issue of making trade-offs between occupational safety and production, and ergonomics should be central to this [37].

Nowadays many companies are undergoing organizational transformations in order to meet the changing of market demands [23]. Thus, in order to become more competitive, SC are adopting new management paradigms to improve SC performance: lean, agile, resilient and green (LARG paradigms) [3].

The lean supply chain seeks waste minimization; the agile supply chain is focused on responding rapidly to market changes; the resilient supply chain has the ability to respond efficiently to disturbances;

and the green supply chain pretends to minimize environmental impacts [20].

The implementation of new production paradigms that reduce work cycle times and task variety, such as lean manufacturing, tend to increase the physiological and psychological strain on workers [23]. Such approaches demand particular care with the issues related with Human Factors, to avoid health and safety problems to workers and losses to companies, due to increase of errors, productivity lost, absenteeism and diminishment of employees' morale, compensations and law suites [23]. Thus, the successful introduction of these new production paradigms depends among others on a Human Factors oriented approach [23].
Ergonomics, also known as Human Factors, is the scientific discipline concerned with understanding the interactions among humans and other elements of a system. It applies theory, principles, data and design methods in order to optimize human wellbeing and overall system performance (IEA cited by [23]). This means that Ergonomics, which is a systems-oriented discipline, seeks to optimize the functioning of systems, through the elimination or at least the diminishing of the incompatibility between workers and their work system, as well as any other safety and health hazards [23].

Thus, human resource is the key factor of organizational success [32]. In this work a conceptual framework integrating ergonomic and occupational safety design principles during the different implementation phases of lean, agile, resilient and green practices is presented.

This paper is organized as follows: after this introduction a literature review related to the combination of Human Factors and LARG organizations/SC is presented. In the third section the conceptual framework is introduced. At the end of the paper, some conclusions are drawn from the presented work.

\section{Literature review}

The lean paradigm is an approach which provides a way to do more and more with less and less (less human effort, less equipment, less time and less space), while coming closer to customer requirements (Womack et al. cited by. [3]). The main purpose of implementing lean manufacturing is to increase productivity, reduce lead time and costs, and improve quality, (Sánchez and Pérez, Karlsson and Åhlström cited by [33]) thus providing the upmost value to customers.

Lean production focus on improving business processes in order to cut costs and serve customers better. This strategy has received attention from ergonomics because implementation of this strategy has been linked to reduced employee well-being [7]. In the following paragraphs a summary of studies combining the lean paradigm and the Human Factors is presented.

A three-year environmental project was implemented at the Petrocart S.A. paper and board mill, through the Danish Support Program for Eastern Europe (DANCEE). The aim was to use "Lean and Green" Production to improve industrial compliance 
with the effluent regulations and with European Integrated Pollution Prevention and Control (EUs IPPC) Directive under implementation in Romania, thereby improving the environmental conditions in the Bistrita River running through the town. In a first phase water saving equipment and biological treatment was installed and in a second phase cleaner technology (Lean and Green) was implemented. The results obtained included better housekeeping (5S and Kaizen) and a Total Quality Management (TQM) organization was implemented where product quality, environment and occupational health and safety were merged into one system [36]. This was the only paper found that combined more than one paradigm (Lean and Green) with Human Factors, in this case, occupational health and safety (OSH).

Two manufacturing lines producing semiconductors using different technology concepts, namely Conventional Line (CL) and Lean Production Line (LPL), were examined by Wong and Richardson [40]. Both lines that manufactured the same products were compared using various factors, including working conditions, task risks and hazards of the job, and physical body stress. Ergonomic approaches were adopted in the investigation of the two lines. Survey questionnaires were administered to $30 \%$ of the workers, and multiple statistical tests were used to determine crucial predictors and to investigate the interactions between the factors. The observed ergonomic differences of the two production lines were compared, and appropriate managerial remedial action was recommended. The research has shown that ergonomics interventions reduced the OSH problems and led to better working conditions, thus increasing job satisfaction. The research also concludes that ergonomics helps to improve productivity, product quality, and employee morale.

Using high-level, three-dimensional computer graphics simulation and other engineering analysis tools, Hunter [14] investigated the advantages of ergonomic tools of one manufacturing system design over another. The study compared lean manufacturing (manufacturing cells) and the functional (job shop) design. Initial research indicated a substantially lower risk of work-related injuries when using the lean manufacturing rather than the functional job shop design; this means that the design of the manufacturing system may inherently reduce or eliminate physiological problems before they develop. Three ergonomic areas - energy expenditure, potential for harmful postures, and potential for repetitive motion disorders - were analyzed from simulated and monitored data on energy expenditure, postures, repetitive motion, and other processing functions, such as cycle time. In all three analyses, the results revealed that the lean production manufacturing cell was superior from an ergonomic point of view over the functional job shop manufacturing system.

Another study examined the relationship between lean job design and work-related musculoskeletal disorder (WRMSD) risk factors [39]. The primary aim of the study was to examine the relationship between lean job design and WRMSD risk at a lean manufacturing plant and compare ergonomic exposure to a traditional plant. The specific aims of the study were to determine: if jobs in the lean plant have an intensified work pace and greater ergonomic risk; and what organizational practices at the lean manufacturing site increase and/or attenuate ergonomic risk factors. A sample of 56 production jobs from each plant was analyzed. The results of this study suggest that lean manufacturing does not necessarily increase workers' WRMSD risk so long as key features of the system are implemented - specifically, a focus on process quality [39].

Guidelines to assess lean production (LP) impacts on working conditions either at a plant or at a departmental level were tested on a harvester assembly line in an American-owned plant in Brazil [33]. The assessment of LP impacts on working conditions was based on multiple sources of evidence, such as face-to-face interviews, questionnaires, direct observations and the analysis of production procedures. The data collected were grouped into four constructs: work content; work organization; continuous improvement; and health and safety. The results indicated that workers considered their working conditions were fairly good and had improved after the introduction of LP.

Today, organizations suffer a tremendous pressure to become more agile, efficient, profitable and dynamic [2]. Since customer requirements are continuously changing and products life cycles are getting shorter, the supply chains must be able to respond quickly to market needs. So, the agile paradigm helps providing the right product, at the right time to the consumer, which is the main objective of any supply chain [1].

Assessing the market attractiveness is considered to be very relevant in the global market scenario, since it can help organizations to gain a greater awareness of market dynamics, speed up the decision process and increase its consistency, thus enabling the strategic alignment and the improvement of the organizational performance [2]. So, Amaral and 
collaborators [2] developed a methodology based on the monitoring information provided by several indicators, resulting in the calculation of Market Attractiveness Indexes. The indicators were selected based on the accessibility of information from different statistical sources (Instituto Nacional de Estatística (INE), Eurostat, OECD, etc.) and on a panel of experts opinions. They applied concepts, tools and techniques traditionally used in the project management field, and explored them within the context of ergonomics and occupational safety and health.

There has been much recent interest within $\mathrm{Hu}-$ man factors in the burgeoning movement of organizational resilience and resilience engineering (Hollnagel et al. cited by [37]). Organizations that follow resilience engineering approach must create processes that are robust yet flexible and use resources appropriately in the face of disruptions or ongoing production and economic pressures [37].

The resilience definition can be twofold: resilience can be an organization's ability to retain or recover rapidly a stable condition, enabling it to pursue its activities during and after a major accident, or in the presence of great and ongoing pressure (Woods, Hollnagel et al., Wreathall cited by [21]) or can focus more on the question of arbitration between safety and production, which means that resilience has the ability to manage great pressure as well as conflicts between safety and production objectives (Hale and Heijer, Flin cited by [21]).

The resilience concept associated with safety was mentioned by several authors: (Foster cited by [18]) defined resilience as an ability to accommodate change without a catastrophic failure, or the ability to absorb shock graceful; (Rosness et al. cited by [18]) adapted the resilience definition to the capacity of an organization to accommodate failures and disturbances without producing serious accidents; (Reason and Hobbs cited by [18]) defined resilience as the properties of an organization to make it more resistant to its operational hazards.

Resilience seems to be a strategic concept dealing with the improvement of safety in complex systems, since it could reconcile the notions of performance and safety rather than systematically oppose them [21].

Some case studies that relate to the resilient paradigm and the Human Factors are presented next.

An article by Morel and collaborators [21] examined several ways of improving safety in the sea fishing activity. A simple modeling of the relationship between resilience and safety was presented, and the choice of strategies for safety-improving interventions considering the system's financial performance and the legal pressure to which professional sea fishing is subject to was discussed. The strategies tested were micro-ergonomics that offered conduct assistance guidelines based on accident analyses of the most serious and frequent causes (collisions while fishing); and macro-ergonomics which compared the safety level of large firms having committed to a Total Quality approach, to that of smaller companies, often privately owned. Neither of the two strategies worked out as expected: the micro-ergonomics anti-collision assistance strategy was misused towards an increase of the fishing objective; and in the macro-ergonomics one of the largest firms suffered less shipwrecks, but a much greater number of work-related injuries.

In the rail engineering context, Wilson and collaborators [37] described a specific project where the notion of a Human Factors case was employed to analyze engineering functions and related uman Factors issues. A Human Factors issues register for potential system disturbances was developed, prior to a Human Factors risk assessment, which jointly covered safety and production (engineering delivery) concerns. Wilson and collaborators [37] also commented on the potential relevance of a resilience engineering perspective to understanding rail engineering systems risk and suggested that a framework of resilience engineering might allow proper consideration of the different trade-offs that must be made in proposals for new rail engineering systems of the future. Resilient systems should have the capability to deliver acceptable levels of service with appropriate levels of protection and at a cost that can be afforded.

Lisbeth and collaborators [18] introduced resilience as an alternative concept for reflecting upon safety. They adapted a model for resilience that was used in a development process but, instead of focusing the analysis on incident reports, they applied a proactive view. The occupational accidents factors they focused on were: sufficient time, knowledge and competence, resources and working environment. The empirical background was a case study on an oil and gas installation in the North Sea that had a negative trend in Lost Time Injury rates. They tried to answer the following research question: How can resilience be built in practice in organizations? and concluded that the three main qualities required for a resilient organization are: anticipation, attention and response.

Environmentally sustainable green SC management has emerged as an organizational philosophy 
by which to achieve corporate profit and marketshare objectives by reducing environmental risks and impacts while improving the ecological efficiency of such organizations and their partners. The increased pressure from community and environmentally conscious consumers had lead to rigorous environmental regulations, forcing the manufacturers to effectively integrate environmental concerns into their management practices (Rao and Holt cited by [3]).

Environmental sustainability, or the 'green movement' has received far more attention recently, and certain strategies and recommendations from interventions designed for promoting proenvironmental behaviors may inform efforts to intervene on critical behaviors for improving occupational safety and health [6].

OSH and environmental sustainability are parallel challenges. The similarities between environmental sustainability and OSH efforts are significant enough that the two may be thought of as major components of the overall concept of sustainability in the workplace. That is, safety should be included as a critical piece of any sustainability effort, and the term sustainability should imply safety as well [6], as discussed in the next studies presented.

A survey of the literature regarding behavioral interventions for both environmental sustainability and occupational safety and health was conducted by Cunningham and collaborators [6]. They first examined each field independently and then assessed areas that overlap. They concluded that improvements in both environmental sustainability and $(\mathrm{OSH})$ require individuals to take action above and beyond the status quo. Also, the similarities between environmental sustainability and $\mathrm{OSH}$ efforts are significant enough that the two may be thought of as major components of the overall concept of sustainability in the workplace. By harnessing the momentum of the green movement and adapting successful intervention approaches from the environmental sustainability domain, OSH leaders may achieve sustainable improvements in worker safety and health. Finally, they recommend that leaders in the respective fields of OSH and environmental sustainability should seek partnerships with these coalitions to benefit from their synergistic cooperation and learn techniques for achieving positive changes in sustainability across domains.

Two case studies from small and medium sized Austrian companies in which cleaner production projects and the implementation of integrated management systems yielded technical, organizational, economic, and public relations improvements [11]. Cleaner production is an effective approach to analyze the productive processes. It aids to reducing use of chemicals and generation of waste and emissions. Simultaneously helps to sensitize workforce and management for environmental problems caused by the enterprise including health and safety. Also, a management system focusing on team work and continuous improvement of quality, environmental aspects and health and safety can help to ensure that once companies leaderships are committed to getting on the continuous improvement journey toward sustainable development, they are more likely to continue on that journey with their employees, suppliers, shareholders, customers and other stakeholders.

In a study developed to understand how managers make decisions involving the elements of sustainability, violations of US Occupational Safety and Health Administration regulations and Toxic Release Inventory reports of emissions were used as proxies for employee well-being and environmental performance. The objective was to understand how the various elements of sustainability relate to each other, especially when examining performance from a triple bottom line perspective (environmental, employee well-being and operational performance outcomes). The results suggested that real improvements in operational performance come by simultaneously focusing on both environmental and employee well-being outcomes. Moreover, in the data set there were a number of companies whose environmental issues also had health and safety implications [26].

From the literature review presented, it becomes clear that the introduction of LARG paradigms in today's organizations must be combined with a $\mathrm{Hu}-$ man Factors approach in order to improve their success. Nevertheless, it was not found a study that introduced Human Factors design principles during the implementation of the four paradigms in an organization reality.

\section{Conceptual framework}

The main goals of Ergonomics when addressing industrial environments are to safely maximize human efficiency; to minimize exposure to recognized ergonomics risk factors; and to proactively strive for continuous program improvement in any design or redesign of products or processes [35]. 
This section presents a conceptual framework that allows integrating ergonomic and safety design principles in the different implementation phases of lean, agile, resilient and green practices.

The present conceptual framework is a generalization of the work done by Nunes and Machado [23] which was based on the integration of an Ergonomic approach in lean manufacturing design and implementation, and where a conceptual building block for lean manufacturing implementation and operation considering ergonomic control block for monitoring the overall system performance was presented.

The conceptual framework presented in Figure 1 consists of an iterative process that combines the implementation of ergonomic and safety design principles with the implementation of LARG paradigm practices.

The design of workplaces must consider its requirements, the target worker population and the ergonomic and safety principles, legislation and standards. This is an iterative process that can be done in the actual workplace or through simulation and/or prototyping of the considered solutions, for instance using CAD applications and other computer aided tools such as decision support systems (e.g., SAMMIE [5], FAST ERGO_X [24], RA_X [22]).
These last tools support the ergonomic and safety risk analysis, help the ergonomist's work and the dialogue with engineers.

When a set or an individual LARG practice is implemented it must be taken into consideration its effects in the human resources of an organization. In order to minimize ergonomic and safety hazards and organizations losses, the work system must be analyzed according to ergonomic and safety principles, and any problems associated with the implementation of LARG practices must be taken care of.

For instance, when a lead time reduction is implemented, which is a lean and resilient practice (see [8]), this change can lead to the reduction of work breaks' duration affecting the workers' recovery period. Another example is the increase in the frequency of production of new product, an agile practice (see [8]) that has an effect on how work is organized and performed, which can lead to an increase in the mental workload imposed to workers.

There are also some LARG practices that can have a positive effect on workers. For instance, the decrease in the quantity and variety of hazardous and toxic materials involved in a manufacturing process, which is a green practice (see [8]) also contributes to improve the health and safety of workers.
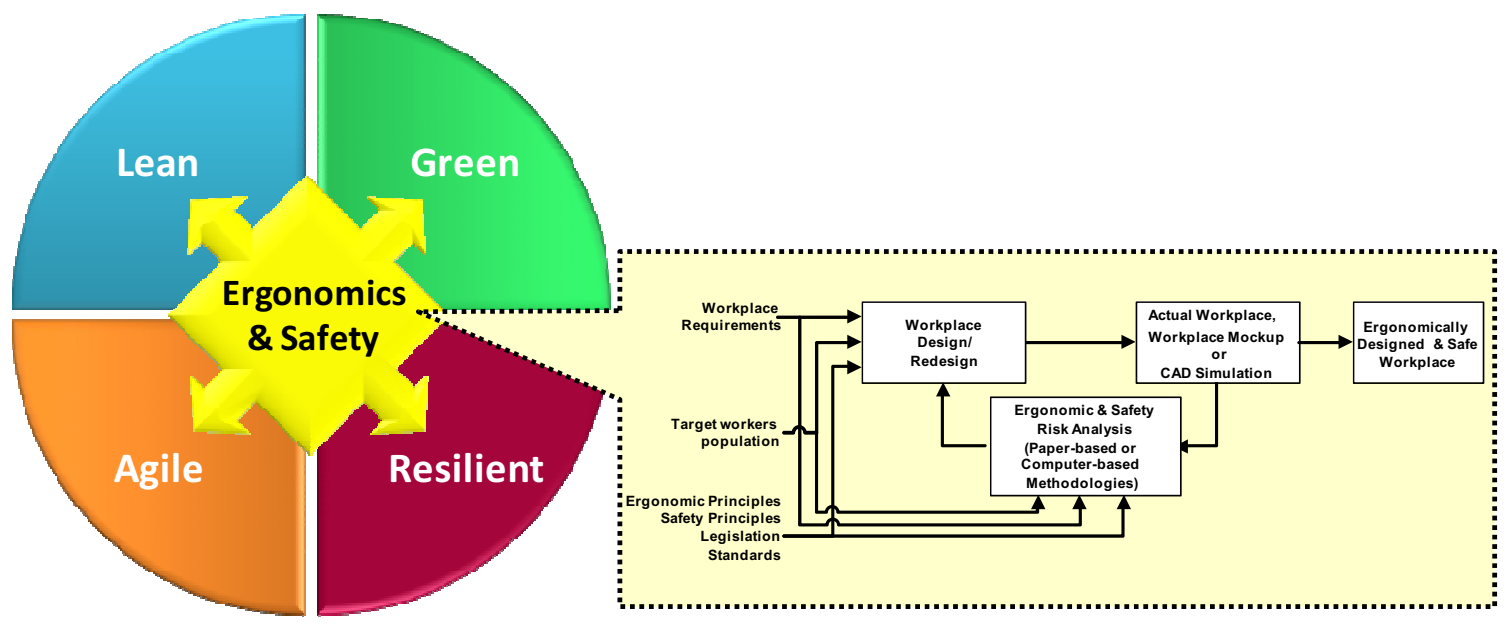

Fig. 1 - Conceptual framework combining the implementation of the ergonomic and safety design principles with the implementation of LARG paradigms practices [25] 


\section{Conclusions}

SC managers are adopting new management paradigms to improve SC performance. These new paradigms, such as lean, agile, resilient and green, tend to increase the physiological and psychological strain on workers [23]. Thus, the introduction of LARG paradigms in today's organizations must be combined with a Human Factors approach in order to improve their success.

Organizational ergonomics covers Human Factors issues in the design of operational structures and the management of organizations [34].

In this work, a conceptual framework that allows integrating the ergonomic and safety design principles during the implementation of LARG practices is presented.

The iterative framework will allow introducing the appropriated ergonomic and safety design principles according to the LARG practices implemented and the effects that this implementation can have in the organization's human resources.

In future research the application of this conceptual model should be done based on a real case study.

\section{Acknowledgments}

This work was funded by the Portuguese Foundation for Science and Technology, project number MITPt/EDAM-IASC/0033/2008.

\section{References}

[1] A. Agarwal, R. Shankar and M. Tiwari, Modeling agility of supply chain, Industrial Marketing Management, 36 (2007), 443-457.

[2] A. Amaral, M. Araújo, P. Arezes, S. Miguel, Market Attractiveness Technique Applied to Ergonomics and the Occupational Safety and Health Area - A case study, 6th International Symposium on Occupational Safety and Hygiene (2010), 61-65.

[3] S.G. Azevedo, H. Carvalho and V.C. Machado, The Influence of LARG Supply Chain Management Practices on Manufacturing Supply Chain Performance, Proceedings of International Conference on Economics, Business and Marketing Management (2011), 1-6.

[4] H. Carvalho and V.C. Machado, Lean, agile, resilient and green supply chain: a review, Proceedings of The Third International Conference on Management Science and Engineering Management (2009), 3-14.

[5] K. Case, M. Porter, M. Bonney, SAMMIE: a man and workplace modelling system, Computer-Aided Ergonomics, Karwowski, W., Genaidy, A. and Asfour, S. eds., Taylor \& Francis, pp. 31-56.
[6] T.R. Cunningham, N. Galloway-Williams and E.S. Geller, Protecting the planet and its people: How do interventions to promote environmental sustainability and occupational safety and health overlap?, Journal of Safety Research 41 (2010), 407-416.

[7] J. Dul and W.P. Neumann, Ergonomics contributions to company strategies, Applied Ergonomics 40 (2009), 745-752.

[8] S. Figueira, V.C. Machado, I.L. Nunes, Ergonomics: a central paradigm in new supply chain management system (to be published).

[9] R. Flin, Erosion of managerial resilience: From Vasa to NASA, in: E. Hollnagel, DD. Woods and N. Leveson, eds., Resilience Engineering: Concepts and Precepts, Ashgate, Aldershot, UK, 2006, pp. 223-233.

[10]H. Foster, Resilience Theory and System Evaluation, in: J.A. Wise, V.D. Hopkin and P. Stager eds., Verification and Validation of Complex Systems: Human Factor Issues, NATO Advanced Science Institutes, Series F: Computer and Systems Sciences, Springer Verlag, New York, 1993, pp. 35-60.

[11]J. Fresner and G. Engelhardt, Experiences with integrated management systems for two small companies in Austria, Journal of Cleaner Production 12 (2001), 623-631.

[12]A. Hale and T. Heijer, Defining resilience, in: E. Hollnagel, DD. Woods and N. Leveson, eds., Resilience Engineering: Concepts and Precepts, Ashgate, Aldershot, UK, 2006, pp. 35-40.

[13]E. Hollnagel, D.D. Woods and N. Leveson, Resilience engineering, Ashgate Publishing Limited, 2006.

[14] S.L. Hunter, Ergonomic Evaluation of Manufacturing System Designs, Journal of Manufacturing Systems 20 (2001/2002), 429-444.

[15]IEA. (2000). Retrieved April 30, 2011, from www.iea.cc.

[16]C. Karlsson and P. Åhlström, Assessing changes towards lean production, International Journal of Operations \& Production Management 16 (1996), 24-41.

[17]D.M. Lampert, J.R. Stock and L.M. Ellram, Fundamentals of Logistics Management, McGraw-Hill, London, 1998.

[18]H. Lisbeth, H.I. Andrade, K. Trond, S. Gaute, Applying the resilience concept in practice: A case study from the oil and gas industry, ESREL 2008 proceedings: Safety, Reliability and Risk Analysis: Theory, Methods and Applications (2009), 733-738.

[19]C. Lloyd and S. James, Too much pressure? Retailer power and occupational health and safety in the food processing industry, Work, Employment \& Society 22 (2008), 713-730.

[20]H. Min, Supply chain modeling: past, present and future, Computers \& Industrial Engineering 43 (2002), 231-249.

[21] G. Morel, R. Amalberti and C. Chauvin, How good micro/macro ergonomics may improve resilience, but not necessarily safety, Safety Science 47 (2009), 285-294.

[22]I.L., Nunes, Fuzzy Multicriteria Model for Ergonomic workplace analysis and Risk analysis, in: Information Technology, Knowledge Management and Engineering for Enterprise Productivity and Quality of Working Life (Proceedings International Conference on Computer-Aided Ergonomics and Safety - CAES'05), Sinay, J. e col. Eds., Kosice, Slovak Republic, 2005, pp. 25-28.

[23]I.L. Nunes and V.C. Machado, Merging Ergonomic Principles into Lean Manufacturing, Proceedings of the 2007 Industrial Engineering Research Conference (2007), 836-841.

[24]I.L., Nunes, FAST ERGO_X - a tool for ergonomic auditing and work-related musculoskeletal disorders prevention, WORK: J. PrevAssessm Rehabil, 34 (2009), 133-148. 
[25]I.L. Nunes, Conceptual model for LARG Integration with Ergonomics and Safety. Working paper of project number MIT-Pt/EDAM-IASC/0033/2008 (2011) (not published)

[26] M. Pagell and D. Gobeli, How Plant Managers' Experiences and Attitudes Toward Sustainability Relate to Operational Performance, Production and Operations Management 18 (2009), 278-299.

[27]D. Piedro, J. Mula, R. Poler and J.L., Verdegay, Fuzzy optimization for supply chain planning under supply, demand and process uncertainties, Fuzzy Sets and Systems 160 (2009), 2640-2657.

[28]P. Rao, and D. Holt, Do green supply chains lead to competitiveness and economic performance?, International Journal of Operations and Production Management, 25(2005), 898-916.

[29] J. Reason and A. Hobbs, Managing Maintenance Error, Ashgate Publishing, Aldershot, USA, 2003.

[30]R. Rosness, G.Guttormsen, T. Steiro, R.K. Tinmannsvik and I.A. Herrera, Organisational accidents and resilient organisations: Five perspectives, SINTEF Industrial Management, Trondheim, 2004.

[31]A. M. Sánchez and M.P. Pérez, Lean indicators and manufacturing strategies, International Journal of Operations \& Production Management 21 (2001), 1433-1451.

[32]F.Ö. Sari, Effects of employee trainings on the occupational safety and health in accommodation sector, Procedia Social and Behavioral Sciences 1 (2009), 1865-1870.

[33]T.A. Saurin and C.F. Ferreira, The impacts of lean production on working conditions: A case study of a harvester assembly line in Brazil, International Journal of Industrial Ergonomics 39 (2009), 403-412.

[34]. Schmid, Organisational ergonomics. A case study from the railway systems area, People in Control: An International Conference on Human Interfaces in Control Rooms, Cockpits and Command Centres (2001), 261-270.

[35]R.T. Smith, Growing an ergonomics culture in manufacturing, Proceedings of the Institution of Mechanical Engineers,
Part B: Journal of Engineering Manufacture (2003), $1027-$ 1030.

[36]A. Vais, V. Miron, M. Pedersen and Jens Folke, "Lean and Green" at a Romanian secondary tissue paper and board mill—putting theory into practice, Resources, Conservation and Recycling 46 (2006), 44-74.

[37]J. Wilson, B. Ryan, A. Schock, P. Ferreira, S. Smith and J. Pitsopoulos, Understanding safety and production risks in rail engineering planning and protection, Ergonomics 52 (2009), 774-790.

[38] J.P. Womack, D.T. Jones and D. Ross, The machine that changed the world, Wilson Quarterly, New York, 1990.

[39] S.K. Womack, T.J. Armstrong and J.K. Liker, Lean Job Design and Musculoskeletal Disorder Risk: A Two Plant Comparison, Human Factors and Ergonomics in Manufacturing 19 (2009), 279-293.

[40] S.B. Wong and S. Richardson, Assessment of Working Conditions in Two Different Semiconductor Manufacturing Lines: Effective Ergonomics Interventions, Human Factors and Ergonomics in Manufacturing \& Service Industries 20 (2010), 391-407.

[41] Y.C. Wong, K.Y. Wong and A. Ali, Key Practice Areas of Lean Manufacturing, 2009 International Association of Computer Science and Information Technology - Spring Conference (2009), 267-271.

[42]D.D. Woods, Essential characteristics of resilience, in: E. Hollnagel, DD. Woods and N. Leveson, eds., Resilience Engineering: Concepts and Precepts, Ashgate, Aldershot, UK, 2006, pp. 21-34.

[43]J. Wreathall, Properties of resilient organizations: An initial view, in: E. Hollnagel, D.D. Woods and N. Leveson, eds., Resilience Engineering: Concepts and Precepts, Ashgate, Aldershot, UK, 2006, pp. 268-2586. 